\title{
Uso da Taxocenose de Peixes como Indicadora de Degradação Ambiental no Rio Paraíba do Sul, Rio de Janeiro, Brasil
}

\author{
Francisco Gerson Araújo
}

Universidade Federal Rural do Rio de Janeiro - Posto de Aqüicultura, Laboratório de Ecologia de Peixes Km 47, Antiga Rodovia Rio - São Paulo, 23.851-970 - Seropédica - RJ - e-mail: gerson@ufrrj.br

\begin{abstract}
An adaptation of index of biotic integrity (IBI) was performed for the first time in Brazil at the Rio Paraíba do Sul, between Barra Mansa and Barra do Piraí, a very important extent of this river because of the high pollution levels, and for being the main abstraction source of Rio de Janeiro city water supply. A monthly standardised sampling programme, from March-1995 to February-1996, was carried out at four sites. Seines, casting nets and net trays were used for catching fishes. IBI was obtained by integrating 12 ecological and environmental attributes of fish taxocene, populations, and individual organisms to assess biological integrity based in Species Composition, Trophic Structure and Fish Condition. Overall, water quality was classified between poor and fair and an improvement was detected between the high polluted Barra Mansa site and the less polluted Barra do Piraí site, showing the capacity of restoration of the river over this $50 \mathrm{~km}$. Seasonally, the best conditions were reached from March to August, and the worse, from September to February, when most aloctone materials are brought to the river.
\end{abstract}

Key words: Paraíba do Sul River, Biotic Integrity, Fish, Pollution

Palavras chave: Rio Paraíba do Sul, Integridade Biótica, Peixes, Poluição

\section{INTRODUÇÃO}

O monitoramento da qualidade da água tem tradicionalmente sido baseado no desenvolvimento de normas e limites para contaminantes específicos geralmente usados em testes de toxidez aguda. O uso desses critérios tem sido criticado em vários campos (Thurston et al. 1979). Tais critérios não têm levado em conta a influência da variação geográfica que naturalmente se verifica nos poluentes, nem considerado o efeito sinergético de numerosos contaminantes ou os efeitos subletais na biologia das espécies. Um outro aspecto que não é considerado no monitoramento dos parâmetros físico-químicos de qualidade da água são os eventos de curto prazo que podem ser críticos no estabelecimento dos impactos bióticos. Finalmente, é impossível medir todos os fatores que podem interferir na integridade biótica, sendo a maioria da literatura sobre poluentes químicos de valor questionável no estabelecimento de padrões de qualidade para os organismos aquáticos (Gosz 1980).
A qualidade da água pode variar de acordo com os usos definidos pela sociedade, os quais incluem abastecimento, lazer e outras utilidades. A habilidade para manter uma taxocenose "equilibrada" é um dos melhores indicadores do potencial para uso humano, sendo também conhecida como integridade biótica. Karr (1981) descreveu, pela primeira vez, uma avaliação de integridade biótica usando a taxocenose de peixes, que tem sido, a partir deste modelo inicial, adaptado em diferentes regiões, visto que a ictiofauna é diferenciada e peculiar para cada local. No trabalho de Karr (op. cit.) é descrita uma rotina de monitoramento da água usando os peixes, que pode, rapidamente e a um baixo custo, servir como uma abordagem exploratória da qualidade do manancial. A comunidade de peixes apresenta numerosas vantagens como indicadora nos programas de monitoramento biótico, citando-se a disponibilidade de informações sobre o ciclo de vida de grande número de espécies, a inclusão de uma variedade de níveis tróficos (omnívoros, herbívoros, insetívoros, planctívoros, carnívoros) compreendendo alimentos tanto de 
origem aquática como terrestre. A posição dos peixes no topo da cadeia alimentar em relação a outros indicadores de qualidade de água também favorece uma visão integrada do ambiente aquático. Além disto os peixes são relativamente fáceis de serem identificados, e situações críticas, como mortalidade, podem ser informadas pelo público em geral, o que pode chamar a atenção para alterações nas condições de qualidade da água dos ambientes.

$\mathrm{O}$ rio Paraíba do Sul, apesar de sua enorme importância como principal bacia hidrográfica entre os dois maiores centros urbano-industriais do país, tem recebido pouca atenção do ponto de vista de estudos dos ecossistemas e pouco tem sido reportado em relação a este ambiente. Estudos em áreas críticas do rio, visando diagnosticar o atual "status" da qualidade da água e detectar eventuais tendências sazonais e/ou de longo prazo, são necessários para subsidiar a elaboração de medidas de monitoramento biótico. Alguns estudos sobre a comunidade de peixes realizados nos últimos anos no rio Paraíba do Sul podem ser destacados. Estudos de biotoxicologia da ictiofauna foram realizados, entre a Represa do Funil e a Barragem de Santa Cecília por Araújo (1983). Caramaschi et al. (1991 apud Mazzoni, 1993) realizaram um levantamento das comunidades e estudos sobre a biologia reprodutiva de alguns grupos mais abundantes, no trecho compreendido entre Três Rios e Campos. Um enfoque ecológico, destacando aspectos de distribuição e abundância de peixes no trecho do médio-baixo rio (Barra do Piraí a Atafona) foi realizado por Araújo et al. (1995) e Araújo (1996).

O presente trabalho tem por objetivo adaptar para o rio Paraíba do Sul o índice de integridade biótica (IIB) desenvolvido por Karr (1981) e examinar suas tendências espaciais e temporais visando seu uso em avaliações de degradação ambiental.

\section{METODOLOGIA}

\section{Área de estudo}

O rio Paraíba do Sul é o maior ambiente lótico da bacia do Leste do Brasil, com extensão de aproximadamente $1000 \mathrm{~km}$ e situa-se entre os dois mais importantes centros urbano-industriais do país (Rio de Janeiro - São Paulo). O trecho estudado (Fig. 1) compreende uma extensão de aproximadamente $50 \mathrm{Km}$, estende-se do município de Barra Mansa ao município de Barra do Piraí (Latitude: $22^{\mathrm{O}} 29^{\prime}$ a $22^{\mathrm{O}} 33^{\prime} \mathrm{S}$; Longitude: $44^{\mathrm{O}} 15^{\prime}$, a $44^{\mathrm{o}} 45^{\prime}$ 'S), e se encontra a aproximadamente $300 \mathrm{~km}$ do Oceano Atlântico. Este trecho, denominado de médio-inferior, é uma região de grande importância estratégica, por encontrar-se nele inserido o maior parque industrial do estado do Rio de Janeiro (Barra Mansa/Volta Redonda), com suas óbvias alterações para a qualidade ambiental do rio. A cerca de 30 quilômetros a jusante deste parque, e também inserido no trecho estudado, encontra-se o sistema de captação de águas da LIGHT Serviços de Eletricidade S/A, bombeando cerca de $160 \mathrm{~m} 3 / \mathrm{s}$, para produção de energia elétrica, cujo manancial é posteriormente utilizado para suprimento da população do município do Rio de Janeiro e adjacências pelo sistema de tratamento do rio Guandu.

\section{Programa de amostragem}

Quarenta e quatro amostragens foram realizadas, entre março de 1995 e fevereiro de 1996, no trecho entre Barra Mansa (estação mais a montante) e Barra do Piraí (estação mais a jusante), cobrindo quatro locais previamente estabelecidos e denominados: Barra Mansa (1BM), Volta Redonda (2-VR), Pinheiral (3-PI) e Barra do Piraí (4-BP), correspondendo aos municípios do trecho do rio onde foram realizadas as amostragens (Fig. 1). Os quatro locais amostrados distam um do outro cerca de 10 a $15 \mathrm{~km}$, e, ao longo do trecho longitudinal do rio, compreendem aproximadamente $50 \mathrm{~km}$.

O fundo é predominantemente areno-lodoso, com profundidade inferior a 1 metro e margens com abundante vegetação ciliar, sendo as amostragens realizadas junto à embocadura de tributários do rio Paraíba. Uma rede, tipo picaré, com malha de $6 \mathrm{~mm}$ entre nós consecutivos, com $2 \mathrm{~m}$ de altura e $10 \mathrm{~m}$ de comprimento, foi utilizada para "fechar" o encontro do tributários com o canal principal do rio. No lado do tributário foram feitas 15 prospecções com peneiras circulares de $70 \mathrm{~cm}$ de diâmetro e malha de $1 \mathrm{~mm}$, e 15 lances de tarrafas, tanto do 
lado do tributários como do lado do canal principal. A tarrafa apresentou malha de $5 \mathrm{~mm}$ de distância entre nós e roda de $6 \mathrm{~m}$ de diâmetro. Ao final das operações com tarrafas e peneiras, a rede de picaré foi recolhida através de um lance no sentido canal principal - tributário.

Considerou-se, para efeitos de cálculo do CPUE (captura por unidade de esforço), uma amostra como o resultado conjunto destas operações de pesca. Foi feita a identificação, contagem e pesagem, bem como observados aspectos de sua anatomia externa para eventual detecção de anomalias, tumores, deformações ou outras doenças.

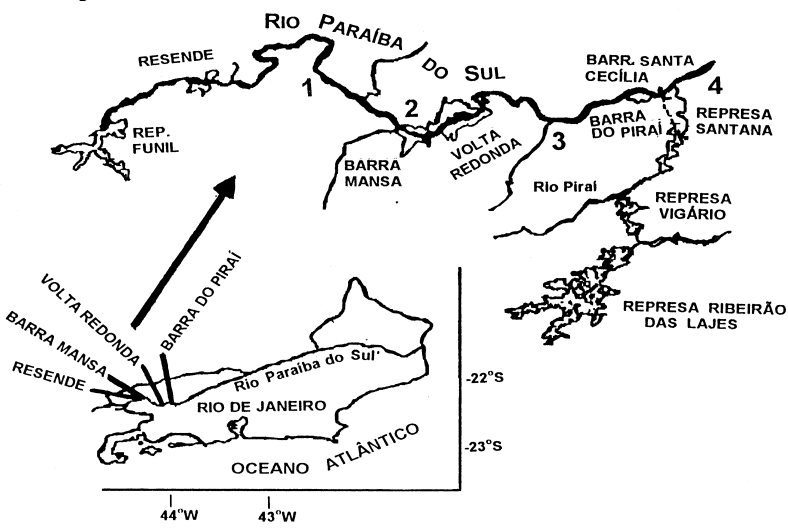

Adaptação do Índice de Integridade Biótica O sistema originalmente proposto por Karr (1981) e adaptado no presente trabalho, pretende descrever o ambiente em seis classes de qualidade de água (Excelente, Boa, Regular, Pobre, Muito Pobre e Sem Peixe). Um critério de pontuação para cada uma destas classes é apresentado na Tabela 1.

O IIB, conforme estabelecido por Karr et al. (1986), baseia-se em vários atributos da taxocenose íctica para avaliar os efeitos de alteração ambiental. Tais atributos cobrem uma amplitude de níveis ecológicos de indivíduos até população, taxocenoses e ecossistemas, e foram agrupados em três categorias: Composição e Riqueza de Espécies, Composição Trófica e Abundância de Peixes, e Condição (Tabela 2). Uma adaptação destas é apresentada para o rio Paraíba do Sul. A cada atributo foi dado uma nota, 5 (situação esperada boa), 3 (situação regular) ou 1 (situação ruim) para acomodar as variações ecológicas e evolutivas inerentes. Os intervalos numéricos entre as classes de integridade também são para acomodar as variações entre valores intermediários de classificação.

Fig. 1. Área de estudo, com indicação dos quatro locais de coleta: 1-Barra Mansa; 2-Volta Redonda; 3-Pinheiral; 4-Barra do Piraí.

Tabela 1. Pontuação de integridade biológica, classes e atributos.

\begin{tabular}{|c|l|}
\hline $\begin{array}{l}\text { Classes de } \\
\text { Integridade (Pontuação) }\end{array}$ & Atributos \\
\hline $\begin{array}{l}\text { Excelente } \\
(57-60)\end{array}$ & $\begin{array}{l}\text { Comparável às melhores situações sem a influência do homem; todas as espécies } \\
\text { regionais esperadas para o habitat e tamanho do curso d'água presentes, } \\
\text { incluindo as formas mais intolerantes, em todas as classes de idade e sexo; } \\
\text { estrutura trófica balanceada. }\end{array}$ \\
\hline $\begin{array}{c}\text { Boa } \\
(48-52)\end{array}$ & $\begin{array}{l}\text { Riqueza de espécies um tanto abaixo da expectativa, especialmente devido à } \\
\text { perda das formas mais intolerantes; algumas espécies com distribuição de } \\
\text { abundância ou de tamanho inferior ao ótimo; estrutura trófica mostra alguns } \\
\text { sinais de estresse. }\end{array}$ \\
\hline $\begin{array}{c}\text { Regular } \\
(39-44)\end{array}$ & $\begin{array}{l}\text { Sinais de deterioração adicionais com menos formas intolerantes, estrutura } \\
\text { trófica mais alterada (p. ex., aumento da frequiência de omnívoros); podem ser } \\
\text { raros os predadores em classes maiores de idade. }\end{array}$ \\
\hline $\begin{array}{l}\text { Pobre } \\
(28-35)\end{array}$ & $\begin{array}{l}\text { Dominada por omnívoros, espécies tolerantes à poluição e generalistas; } \\
\text { espécies híbridas e/ou doentes sempre presentes. }\end{array}$ \\
\hline $\begin{array}{l}\text { Muito Pobre } \\
(<24) \text { poucos ictiófagos; taxas de } \\
\text { crescimento e fator de condição } \\
\text { diminuídos }\end{array}$ & $\begin{array}{l}\text { Poucos peixes presentes, principalmente introduzidos, ou de espécies muito } \\
\text { tolerantes; híbridos freqüentes; comuns doenças, parasitas, nadadeiras feridas e } \\
\text { outras anomalias. }\end{array}$ \\
\hline $\begin{array}{l}\text { Sem peixe } \\
(0)\end{array}$ & \begin{tabular}{l} 
Repetidas pescarias sem capturar qualquer peixe. \\
\hline
\end{tabular} \\
\hline
\end{tabular}


Tabela 2. Pontuações utilizadas na determinação da Integridade Biótica para comunidades de peixes do rio Paraíba do Sul, RJ

\begin{tabular}{lccc}
\hline Categoria & $\mathbf{5}$ & Pontuação & $\mathbf{1}$ \\
& & $\mathbf{3}$ & $<40$ \\
\hline 1. Número de espécies & $>80$ & $40-80$ & 0 \\
2. Presença de espécies intolerantes & $>2$ & 1 & $<15$ \\
3. Número de Characiformes & $>30$ & $15-30$ & $<20$ \\
4. Número de Siluriformes & $>40$ & $20-40$ & $<2$ \\
5. Número de Perciformes & $>4$ & $2-4$ & $<16 \%$ \\
6. Proporção de espécies muito tolerantes & 0 & $1-16 \%$ & $>45 \%$ \\
COMPOSIÇÃO TRÓFICA & & 20 a $45 \%$ & $0 \%$ \\
7. Proporção de Omnívoros & $<20 \%$ & $1 \%$ & $0 \%$ \\
8. Proporção de Invertívoros & $>2 \%$ & $1-2 \%$ & $<48$ \\
9. Proporção de Ictiófagos & $>3 \%$ & $48-80$ & $0 \%$ \\
ABUNDẤNCIA E CONDIÇÃO DOS PEIXES & & $1-6 \%$ & $>3 \%$ \\
10. Número de Indivíduos & $>80$ & $1-2 \%$ & \\
11. Proporção de peixes de piracema & $>6 \%$ & $0 \%$ & \\
12. Proporção de peixes com anomalias, doenças, etc & & & \\
&
\end{tabular}

Os atributos 1, 3, 4 e 5 da Tabela 2 foram estabelecidos para o rio Paraíba do Sul, com base na compilação de espécies para a rio (Fowler 1948, 1950, 1951 e 1954), em Menezes (1972), Britski (1972; 1994), Bizerril (1994) e conforme metodologia descrita por Fausch et al. (1984). Estabeleceu-se como 120 o número de espécies do rio Paraíba em uma situação "inalterada", portanto antes dos efeitos das modificações introduzidas ao longo deste século, quando ocorreram as alterações mais significantes, como a instalação do parque industrial de Volta Redonda e adjacências, as barragens para produção de energia hidrelétrica, a construção da rodovia Presidente Dutra e o desenvolvimento em larga escala do cultivo da cana-de-açúcar, dentre outras. Fowler (op. cit.) compilou cerca de 100 espécies para o rio, e Britski (1994) estimou em 122 o número de espécies da Bacia e estabeleceu a proporção dos grupos dominantes (subordens Characoidei - 37,7\%, Siluroidei - 49,2\%, Gymnotoidei - 1,7\%, a família Cichlidae - 4,9\%, a ordem Cyprinodontiformes - 4,9\% e os invasores marinhos - 1,7\%). Esta proporção foi utilizada para o cálculo dos ítens 3, 4 e 5, partindo-se do máximo esperado de espécies, e dividindo em três faixas, similarmente ao "trisected lines" de Karr et al. (1986). Por exemplo, o número de espécies (atributo 1) estabelecido para condições "inalteradas" do rio de 120 , foi dividido em três faixas (80-
$120=$ situação excelente, pontuação $5 ; 40-80$ $=$ situação regular, com evidentes indicações de alterações, pontuação 3; e $<40=$ situação muito alterada com pobre qualidade de água, pontuação 1). $\mathrm{O}$ número de indivíduos (atributo 10), por ser dependente do esforço amostral foi arbitrado com base na amplitude de variação das amostras, considerando-se amostras regulares aquelas que contivessem entre 48 e 80 indivíduos (atributo 10), com 1 a $6 \%$ de peixes de piracema (atributo 11). Os outros atributos (2, 6 e 12) e as proporções de peixes por composição trófica (atributos 7, 8 e 9) seguiram os padrões estabelecidos por Karr (1981), Fausch et al. (1984) e Karr et al. (1986).

\section{Tratamento estatístico}

Comparações espaciais e temporais do Índice de Integridade Biótica foram efetuadas através da Análise de Variância Bi-Fatorial, tomando como fatores espaciais, os quatro locais de coleta, e como fatores temporais, as quatro estações do ano. Para as médias que apresentaram diferenças significativas ao nível de $95 \%$ de confiança $(\mathrm{p}<0,05)$, o teste "a posteriori" de Student-Newmam-Keuls (SNK) foi aplicado para determinação de quais valores foram estatisticamente diferentes. As médias foram apresentadas graficamente com sua medida de variabilidade indicada sob a forma de $+/-1$ erro padrão. 
A normalidade e a homogeneidade das pontuações do Índice de Integridade Biótica foram determinadas através do teste de Bartlet (Sokal \& Rolf 1981), e, como foi encontrado que a maioria dos dados não atendia a estes requisitos, utilizou-se a transformação logarítmica decimal Log $(x+1)$. Tais transformações foram efetuadas previamente à análise de variância.

\section{RESULTADOS}

\section{1 - Adaptação do Índice de Integridade Biótica}

\section{Composição de espécies}

Foram identificadas 26 espécies, compreendendo 22 gêneros e 11 famílias como resultado das 44 amostragens nos 4 locais de coleta do rio Paraíba do Sul entre março - 1995 e fevereiro - 1996. A lista de espécies, em ordem decrescente de abundância numérica é apresentada na Tabela 3.

As espécies foram classificadas como tolerantes/intolerantes e por hábitos alimentares (Tabela 4). Foram consideradas intolerantes aquelas que atualmente raramente são capturadas e, quando ocorrem nas capturas, é praticamente impossível conduzi-las vivas ao laboratório. Os hábitos alimentares foram determinados conforme informações da literatura (Britski 1972), tendo sido efetuada o exame preliminar de alguns conteúdos estomacais, visando confirmação.

\section{Composição Trófica}

Três medidas tróficas são utilizadas no presente sistema. Um local declina em qualidade à medida que aumenta a proporção de indivíduos omnívoros. A dominância dessas espécies cresce presumivelmente como resultado da

Tabela 3. Número, peso total e respectivos percentuais das espécies de peixes coletadas no rio Paraíba do Sul, entre Barra Mansa e Barra do Piraí, entre Fevereiro-1995 e Março-1996.

\begin{tabular}{|c|c|c|c|c|}
\hline ESPÉCIES & Número & $\% \mathrm{~N}^{0}$ & Peso & $\%$ Peso \\
\hline Geophagus brasiliensis & 780 & 27,4 & 31188,4 & 68,1 \\
\hline Lebistes reticulatus & 667 & 23,4 & 214,0 & 0,5 \\
\hline Rineloricaria $\mathrm{sp}$ & 351 & 12,3 & 2338,5 & 5,1 \\
\hline Astyanax bimaculatus & 190 & 6,7 & 352,6 & 0,8 \\
\hline Poecilia vivipara & 157 & 5,5 & 99,0 & 0,1 \\
\hline Astyanax parahybae & 156 & 5,5 & 270,9 & 0,6 \\
\hline Phalloceros caudimaculatus & 138 & 4,8 & 110,1 & 0,2 \\
\hline Hypostomus affinis & 120 & 4,2 & 3854,3 & 8,4 \\
\hline Oligosarcus hepsetus & 61 & 2,1 & 545,0 & 1,2 \\
\hline Pimelodus maculatus & 40 & 1,4 & 2360,1 & 5,1 \\
\hline Callichthys callichthys & 38 & 1,3 & 449,6 & 0,9 \\
\hline Corydoras nattereri & 29 & 1,0 & 1076,8 & 2,3 \\
\hline Astyanax giton & 16 & 0,6 & 25,6 & 0,1 \\
\hline Leporinus copelandii & 16 & 0,6 & 854,2 & 1,9 \\
\hline Hoplias malabaricus & 14 & 0,5 & 54,0 & 1,2 \\
\hline Hyphessobrycon bimaculatus & 12 & 0,4 & 63,9 & 0,1 \\
\hline Rhamdia parahybae & 12 & 0,4 & 612,5 & 1,3 \\
\hline Astyanax intermedius & 11 & 0,4 & 18,9 & 0,1 \\
\hline Cyphocharax gilberti & 11 & 0,4 & 144,2 & 0,3 \\
\hline Tilapia rendalli & 7 & 0,2 & 72,6 & 0,1 \\
\hline Crenicichla lacustris & 6 & 0,2 & 278,5 & 0,6 \\
\hline Deuterodon $\mathrm{sp}$ & 5 & 0,2 & 10,5 & 0,1 \\
\hline Gymnotus carapo & 5 & 0,2 & 163,4 & 0,4 \\
\hline Synbranchys marmoratus & 4 & 0,1 & 91,0 & 0,2 \\
\hline Hartia loricariformes & 2 & 0,1 & 30,3 & 0,1 \\
\hline Loricariichthys spixii & 1 & 0,1 & 26,9 & 0,1 \\
\hline TOTAL & 2849 & 100,0 & 45796,6 & 100,0 \\
\hline
\end{tabular}

Tabela 4. Relação de tolerâncias e hábitos alimentares para peixes por ordens no Rio Paraíba do Sul. 
TOLERANTES

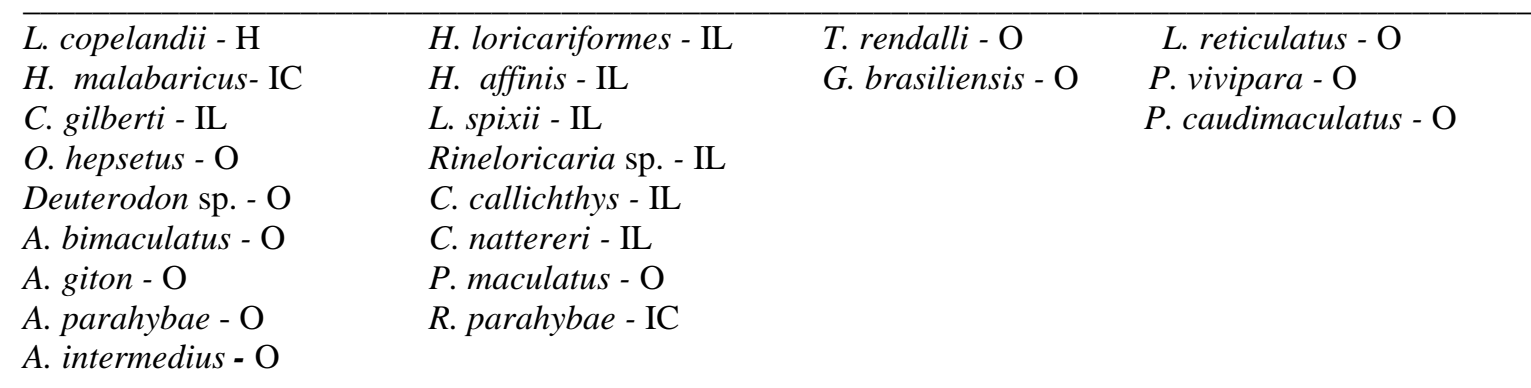

INTOLERANTES

\begin{tabular}{llll}
\hline H. bifasciatus - IN & G. carapo - IN & C. lacustris - IN & S. marmoratus - IC \\
\hline
\end{tabular}

HÁBITO ALIMENTAR: IC = ICTIÓFAGO; H = HERBÍVORO; IL = ILIÓFAGO; O = OMNÍVORO IN= INVERTÍVORO; $\mathrm{P}=$ PLANCTÍVORO.

degradação da base alimentar, especialmente dos invertebrados. Em consequiência, sua oportunística forragem ecológica torna-os bem sucedidos em relação aos forrageiros mais especializados. Tem sido estabelecido por Karr (1981) que amostras com menos de $20 \%$ de indivíduos omnívoros são consideradas boas, enquanto aquelas com mais de $45 \%$ de omnívoros são gravemente degradadas.

Outro critério é a proporção da comunidade de peixes insetívoros, ou consumidores de invertebrados em geral (invertívoros). Em geral, existe uma forte correlação negativa entre a abundância de peixes insetívoros (ou invertívoros) e os omnívoros.

A presença de ictiófagos é outro indicador importante. Populações viáveis e saudáveis de espécies ictiófagas de topo, como Synbranchus marmoratus, Hoplias malabaricus e Rhamdia parahybae indicam uma comunidade saudável e diversificada. Com o declínio da qualidade da água, essas populações diminuem e/ou desaparecem.

\section{Abundância e condição dos peixes}

Elevadas capturas por unidade de esforço (CPUE) são freqüentemente associadas com rios ricos e de boa qualidade de água, enquanto que baixas CPUEs são comuns em sistemas fortemente degradados. A abundância de peixes é peculiar de cada sistema, sendo um reflexo da capacidade do rio suportar uma comunidade aquática. Reduções no número esperado de indivíduos para um determinado esforço de amostragem poderiam estar indicando alguma forma de estresse que estaria afetando os requerimentos de sobrevivência de uma comunidade de peixes (Paller et al. 1996).

Um outro importante critério que parece ser útil na classificação de um ambiente é a frequiência de peixes com tumores, lesões nas nadadeiras ou deformidades, parasitas e outros indicadores de doenças ou anomalias. $\mathrm{O}$ rio Paraíba do Sul contém um número incomum de peixes com anormalidades associadas a uma variedade de poluentes (Araújo 1983).

\section{2 - Variações espaciais e temporais}

Foi encontrado através da ANOVA que o IIB variou entre as estações do ano $(\mathrm{F}=6,1)$, porém não entre os locais de coleta $(\mathrm{F}=2,8)$, nem apresentou significantes interações estações do ano-locais de coleta $(\mathrm{F}=2,1)$. No outono foram registrados os maiores valores (média $=34,8$ ), os quais foram significantemente $(\mathrm{p}<0,01)$ superiores ao verão, primavera e inverno (médias $=25,3$ $31,0)$. As classes de integridade variaram de Muito Pobre, nos meses do verão, a Regular no mês de abril (Fig. 2). 
Espacialmente, embora sem apresentar diferenças estatisticamente significantes ( $p>0,05$ ), as menores médias do IIB foram obtidas para a estação mais a montante (Barra Mansa), tendo aumentado nas estações mais a jusante de Volta Redonda e Pinheiral, e atingido o máximo em Barra do Piraí, indicando uma

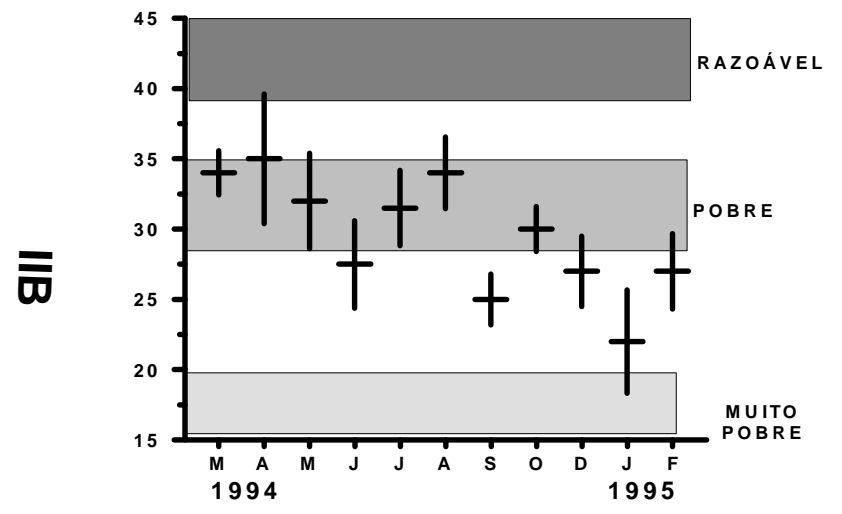

Fig. 2. Variação temporal do Índice de Integridade Biótica - IIB, com indicações das classes de qualidade de água.

melhoria da qualidade da água à medida que o rio se afasta dos locais de introdução de maior carga poluente de Barra Mansa e Volta Redonda (Fig. 3). As classes de integridade variaram de Muito Pobre, na estação de Barra Mansa, a Pobre/Regular, em Barra do Piraí.

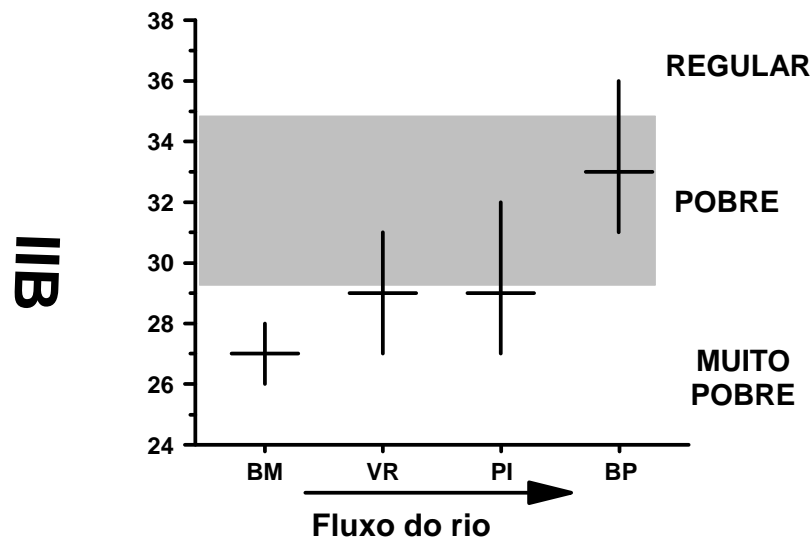

Fig. 3. Variação espacial do Índice de Integridade Biótica - IIB, com indicações das classes de qualidade de água.

\section{DISCUSSÃO}

O rio Paraíba do Sul apresentou, conforme classificação do Índice de Integridade Biótica - IIB, água de baixa qualidade ao longo do trecho estudado entre Barra Mansa e Barra do Piraí, cujas classes variaram entre Pobre e Muito Pobre. Dentre os mais importantes fatores que contribuíram para esta situação, destaca-se o parque industrial instalado nesta área, o qual é composto por indústrias de grande porte, três siderúrgicas, além de indústrias químicas produtoras de pesticidas, solventes clorados e orgânicos sintéticos diversos, bem como indústrias metalúrgicas, e outras de menor porte. Além disto, também contribui para a diminuição da qualidade da água, resultando na diminuição do número de espécies e quantidade de peixes, a construção de barragens interrompendo o curso natural do rio, o que impossibilita a migração de cardumes na época da desova e ocasiona freqüentes mudanças no nível e velocidade das águas do rio. Atividades de mineração também degradam o fundo do rio, e a canalização de determinados trechos elimina as lagoas marginais que servem como áreas de criação para grande número de espécies de peixes. Uma grande vantagem do uso do IIB é sua qualidade de integrar diversos atributos ecológicos, evitando a seleção de um determinado critério isolado que possa resultar em diagnósticos menos confiáveis do que um conjunto de medidas (Karr et al. 1986).

A escolha do número de espécies como critério inicial é fundamental, uma vez que esta medida é o resultado de natureza biogeográfica, sazonal e característica da área. Medidas de diversidade tipicamente ignoram a composição das espécies das taxocenoses amostradas, sendo as características da espécie irrelevantes para tais índices, embora a identificação correta seja um requisito importante. Com o IIB, várias medidas de composição das espécies são avaliadas. Cada espécie de peixe tem tolerâncias características à qualidade da água, habitat e outras condições. Assim, dentro de cada grupo de peixes, coleções de espécies podem ser listadas por suas tolerâncias. 
A presença de espécies intolerantes é um critério importante. Em cada área geográfica, algumas espécies facilmente identificáveis são as primeiras a desaparecer com o aumento da influência do homem. O desaparecimento pode ser atribuído à degradação da qualidade da água, degradação do habitat ou à combinação dos dois. Exemplos de espécies intolerantes encontradas no rio Paraíba do Sul incluem a pescada de água doce (Pachypops transversus) e as matrinchãs (Brycon sp.) que raramente são encontradas, já tendo desaparecido das pescarias comerciais há décadas (Araújo 1996).

A presença de espécies de piracema deve ser igualmente considerada, uma vez que realizam migrações reprodutivas para desovar nas partes superiores dos rios. Com o barramento dos rios, uma significante alteração ambiental, e com a diminuição dos locais de desova devido à erosão das margens, siltação dos córregos e redução de tributários onde as desovas são realizadas, estes peixes tornam-se ameaçados de extinção e ocorrem cada vez menos nos rios. Este critério (presença de espécies de piracema) foi escolhido para substituir o critério presença de híbridos, sugerido por Karr (1981).

Outra medida é a presença de espécies altamente tolerantes, como os barrigudinhos ou guarus (Cyprinodontiformes), um vez que eles são característicos de locais degradados. Elevada abundância dessas espécies (> 20\% do total de indivíduos) indica condições degradadas. Estes peixes são mais tolerantes e permanecem nos locais muito depois que todos os demais desaparecem.

Um importante indicador da qualidade de água de um sistema pode ser obtido pelo exame da estrutura trófica da comunidade. Alterações na qualidade da água ou outras condições do habitat, inclusive o uso da terra na bacia hidrográfica, podem resultar em diminuição ou eliminação de muitos recursos alimentares para os peixes. As consideráveis mudanças na comunidade de peixes podem, assim, ser detectadas.
Embora não tenham sido observadas diferenças espaciais estatisticamente significantes, o IIB foi bastante eficiente para indicação da qualidade da água com a predominância das Classes Pobre e Muito Pobre em Barra Mansa, passando a Pobre em Volta Redonda e Pinheiral, e atingindo sua melhor qualidade, entre Pobre e Regular, em Barra do Piraí. Tais diferenças podem estar indicando um gradiente espacial de melhoria da qualidade da água do rio em seu trecho mais crítico, de Barra Mansa para Barra do Piraí, com os efeitos da poluição sendo amortecidos gradativamente rio abaixo, indicando uma certa capacidade de recuperação do mesmo.

Águas de melhor qualidade foram detectadas entre março e agosto, e as piores, entre setembro e fevereiro. Nesses últimos meses ocorreram também os maiores índices pluviométricos (Barbieri \& Kronemberger 1994), o que pode estar carreando maior quantidade de material alóctone para o rio, contribuindo para a diminuição da qualidade da água, com reflexos negativos na integridade biótica. Há que considerar também, que durante este último período as amostragens são mais dificultadas, o que pode contribuir para uma tendência de diminuição do índice. $\mathrm{O}$ uso de diferentes tipos de equipamentos tende a diminuir tais distorções, fornecendo as bases para comparações espaciais e temporais. Os locais de coleta escolhidos são caracterizados como áreas de ligação de tributários ao canal principal do rio e representam locais onde as condições de aglomeramento de peixes são favorecidas, especialmente os jovens, uma vez que são locais mais rasos, oferecendo uma maior variedade de nichos tróficos, servirem como área de proteção, além de serem ricos em materiais alóctones trazidos pelo tributário para o rio principal.

A inclusão do IIB em programas de monitoramento pode servir para detectar tendências espaciais e temporais de qualidade de água, sendo um instrumento eficiente nos programas de conservação e gerenciamento dos ecossistemas aquáticos brasileiros. Após seu desenvolvimento inicial por Karr (1981) para rios do estado de Illinois, este índice foi 
adaptado e incluído como avaliador de qualidade de água, juntamente com os parâmetros físico-químicos tradicionais, em vários estados dos Estados Unidos e Europa Ocidental (Karr \& Kerans 1994; Karr et al. 1986; Oberdorff \& Hughes 1992). No rio Paraíba do Sul, a adaptação do Índice de Integridade Biótica pareceu refletir eficientemente a qualidade da água, apresentado tendências que coincidiram com as expectativas de alteração do rio face o volume da carga poluente introduzida neste trecho altamente modificado por ação antrópica.

\section{REFERÊNCIAS}

Araújo, F.G. (1996), Composição e estrutura da comunidade de peixes do médio e baixo rio Paraíba do Sul, RJ. Rev. Bras. Biol., 56, 111126.

Araújo, F. G.; Santos, A. C. A. \& Simoni, M. R. F. (1995), Variação espacial e temporal da comunidade de peixes do médio e baixo rio Paraíba do Sul, RJ. Rev. Univ. Rural. Sér. Ciênc. da Vida, 17, 61-73.

Araújo, J. R. S. (Coord.). (1983), Projeto de biodetecção de tóxicos em sistemas fluviais de utilização em captação de água para sistemas públicos de abastecimento. Cadernos FEEMA, Série Congressos. 17/83 (DEPEA/DNH).

Barbieri, E. B. \& Kronemberger, D. M. (1994), Climatologia do litoral sul-sudeste do Estado do Rio de Janeiro (um subsídio à análise ambiental). Cad. Geociências, 12, p.57-73.

Bizerril, C. R. S. F. (1994), Analise taxonômica e biogeografica da ictiofauna de água doce do leste brasileiro. Acta Biol. Leopoldensia, 16, 51-80. 1994.

Britski, H. A. (1972), Peixes de água doce do estado de São Paulo - Sistemática. In. Comissão Interestadual da Bacia ParanáUruguai, Poluição e Piscicultura. Faculdade de Saúde Pública USP e Inst. de Pesca: São Paulo. Pp. 79-112.

Britski, H. A. (1994), A fauna de peixes brasileiros de água doce e o represamento de rio. COMASE/ELETROBRÁS, Seminário sobre fauna aquática e o setor elétrico brasileiro. Caderno 1. Fundamentos. Pp. 2330.

Fausch, K.D.; John. L.; James, R. K. \& Paul. L. A. (1984), Fish Communities as indicators of Environmental Degradation. American Fisheries Society Symposium, 8, 123-144.

Fowler, H. W. (1948), Os peixes de água doce do Brasil. I. Arq. Zool., 6, I-XII, 1-204.

Fowler, H. W. (1950), Os peixes de água doce do Brasil. I. Arq. Zool., 6, I-XII, 205-404.

Fowler, H. W. (1951), Os peixes de água doce do Brasil. I. Arq. Zool., 6, I-XII, 405-625.

Fowler, H. W. (1954), Os peixes de água doce do Brasil II. Arq. Zool, 9, I-XII, 1-400.

Gosz, J. R. (1980), The influence of reduced streamflows on water quality. In. Energy development in the Southwest. eds. W. O. Spofford, Jr.; A. L. Parker \& A.V.Kneese.2, Resources for the Future, Washington D.C.,Pp.3-48.

Karr, J. R. (1981), Assessment of biotic integrity using fish communities. Fisheries, 6, 21-27.

Karr, J.R.; Fausch, K.D.; Angermier, P.L.; Yant, P.R. \& Schlosser, I. J. (1986), Assessing biological integrity in running waters, a method and its rationale. Spec. Public., 5. III. Nat. Hist. Surv.

Karr. J. R. \& Kerans, B. L. (1994), A benthic index of biotic integrity (B-IBI) for rivers of the Tennessee Valley. Ecol. Applications, 4, 768-785.

Mazzoni, R. (1993), Estratégia reprodutiva de duas espécies de Hypostomus Lacépède, 1803, (Siluroidei, Loricariidae) no trecho inferior do rio Paraíba do Sul, Rio de Janeiro. Dissertação de Mestrado. Programa de pós graduação em Ecologia. Universidade Federal do Rio de Janeiro, Rio de Janeiro, $130 \mathrm{p}$.

Menezes, N. A. (1972), Distribuição e origem da fauna de peixes de água doce das grandes bacias fluviais do Brasil. In. Comissão Interestadual da Bacia Paraná-Uruguai, Poluição e Piscicultura. Faculdade de Saúde Pública USP e Inst. de Pesca: São Paulo. Pp. 73-78.

Oberdorff, T. \& Hughes, R. M. (1992), Modification of an index of biotic integrity based on fish assemblages to characterize rivers of the Seine Basin, France. Hidrobiologia, 28, 117-130.

Paller, M. H.; Reichert, M. J. M. \& Dean, J. M. (1996), Use of fish communities to assess environmental impacts in South Carolina coastal plain streams. Trans. Amer. Fish. Soc., 125, 633-644.

Sokal, R. R. \& Rohlf, F. J. (1981), Biometrics: the principle and practice of statistics in biological research. W. H. Freeman \& Co., San Francisco, 2ed. 776p. 
Thurston, R.V.; Russo. R. C.; Fetterolf-Jr, C. M.; Edsall, T. A. \& Barber-Jr, Y. M. (1979), A review of the EP Red Book. Quality criteria for water. Water quality Sec., American Fisheries Society, Bethesda, Maryland, $313 \mathrm{p}$.

Received: May 12, 1998;

Revised: May 18, 1998; Accepted: October 16, 1998. 